\title{
The Operating Efficiency under the Decreasing Rate of School Students for Public and Private High Schools in Xindian District of New Taipei City: Bootstrap DEA Model
}

\author{
Hsiang-Hsi Liu ${ }^{1} \&$ Fu-Hsiang Kuo ${ }^{2}$ \\ ${ }^{1}$ Graduate Institute of International Business, National Taipei University, New Taipei City, Taiwan \\ 2 Department of Information Management, Chaoyang University of Technology, Taichung City, Taiwan \\ Correspondence: Fu-Hsiang Kuo, Department of Information Management, Chaoyang University of Technology, \\ Taichung City, Taiwan.
}

Received: October 23, 2017

Accepted: November 7, 2017

Online Published: November 16, 2017

doi:10.5430/ijba.v8n7p98

URL: https://doi.org/10.5430/ijba.v8n7p98

\begin{abstract}
The goal of this research is to evaluate the low fertility affects school efficiency of high school in Taiwan. Based on Trend Forecasting Model (TFM) and Bootstrap Data Envelopment Analysis (DEA). The empirical results of this research indicate the following results: (1) we utilize our proposed TFM model to study the annual change of student's population, from 2011 to 2016 . The results show that the number of students is indeed reduced year by year in New Taipei City, but the number of declines is not great, from 2011 to 2016. Conversely, the number of student's declines have great, from 2016 to 2017. (2) The results of the low fertility problem factors caused school of total efficiency to fall below 1. In addition, the government also proposes to raise the fertility policy, for example, the government subsidies schools of tuition. It implies that the larger the school, the economics of scale can be accomplished when outputs expand (such as the number of students (output variable)) and then cause school's operational efficiency. In contrast, the low fertility problem brings about the number of students (output variable) decreased may directly affect school of scale efficiency and causing the schools total efficiency to fall below 1 . The results of this research can also be the reference for educational authorities when formulating policies and regulations for promoting.
\end{abstract}

Keywords: Data Envelopment Analysis, Bootstrap DEA Model, operational performance, based on Trend Forecasting Model

\section{Introduction}

Even low fertility causes the numbers of high school students to decrease in Taiwan, the school and government agencies still need promote educational marketing to improve school operational efficiency.

Due to the decline and change in the fertility rate of the population of Taiwan, resulting change population structure in Taiwan. This problem will affect many aspects, such as country, business, education, family, and individual. In education, the most direct impact on the school is the lack of students and cause the school of a decrease in student enrolment. Finally, it will to a direct impact on school management and operating efficiency issues. Such as enrolments difficulties, reduce classes, add the teacher's surplus, more vacant school premises, and the waste of educational resources etc. The reduction in students may directly affect school management and operating efficiency issues. Therefore, there will more and more to the closing down of schools. Therefore, the Government very attach to importance to this issue and to integrate the various organs and agencies to formulate effective policies and solved this population problem. Unfortunately, the Government has not formulated effective policies and solved this population problem. Indeed, since 2013, there will be more than 50,000 of student vacancy, due to the decrease in student enrolments in Taiwan, and resulting in the country has more than 17 high school of students less than 600, and may directly affect the school management. Even more worrying is that after three years, the number of junior graduate students will be reduced from 300,000 to 190,000 in Taiwan. Its problem will lead to the management difficulties of the school and face closure of schools. In other words, the operational efficiency of high schools may also be lower and reduce their competitiveness.

The studies of the analysis of school competitiveness are long being the important issues at the industry, government, and academic levels. To manage a successful school, it must be able to deal with the rapid change of expectation both 
from the society and from the parents. It is obvious that if the school is not catching up the rapid socioeconomic and environmental changes, it is inevitable that school managements will face greater challenges, and unless schools maintain pace with the changes in the educational system, they are bound to be caught in an operational crisis. However, few studies have attempted a competitiveness analysis of the operating efficiency of the decreasing rate of school students for public and private high schools and the theoretical foundation for the same is insufficient. Hence, the objective of this study is to furtherly investigate educational practices at Taiwan's schools, to identify suitable case studies for detailed analysis and specific actions for enhancement. Thus, we analyse the operational performance of public and private vocational and senior high schools before and after the operating efficiency under the decreasing rate of school students. To do so, this study also investigates estimate of population trends and the operational performance of selected public and private vocational and senior high schools in the Xindian District of New Taipei City.

This study is quantitative in nature and uses two analytical models, namely, firstly, this section will adopt the TFM model to modelling by 2011 to 2016 data and then establishing forecast model to forecast population trends from 2017 to 2019. Furthermore, this study applies Bootstrap DEA model to analyse the relative efficiencies of schools and under the decreasing rate of school students whether really lead to change the efficiency of school management. The input and output variables of various categories are selected which based on relevant literatures and computed by statistical software. We hope that the results of this analysis can serve as a reference for schools in setting up performance improvement strategies and for government agencies in formulating related policies and measures.

The remaining of this paper is organized as follows: Section 2 describes literature reviews. Section 3 provides Study model. Section 4 analyses empirical results. Finally, we conclude the paper in Section 5.

\section{Review of Literature}

Briefly, Demographic structure describes the age distribution of a population and thereby is also called population age structure. It is usually measured by the total dependency ratio, which is the ratio of the total number of the dependent population, aged below 15 and above 65 years, to that of the working-age population. During recent years there has been an increasing awareness of a direct influence of change population structure on the macro economy. Just as Culter et al. (1990) pointed out that declining fertility is one of the most important sources causing demographic change. With fertility declining and population life expectancy increasing, some countries are facing an increasingly serious problem of population aging. All of the developed countries, just like Japan, where the population aging is serious, have experienced an economic slowdown or economic recession to varying degrees. Some research shows that the low fertility directly affects population aging causes a rise in the dependency ratio, labor shortages, aging of the labor structure and social security burdens. All of these factors have a negative effect on economic growth (Faruqee \& Mühleisen, 2002; Lindh \& Malmberg, 1999; MacKellar et al., 2004).

This partly explain that the low-fertility countries tend to fall in two distinct groups, those where the TFR has stayed above 1.5 and those where it has fallen and remained below this critical level (McDonald, 2005).There are currently 28 countries with TFRs below 1.5, and a recent UN compendium on national population policies indicates that the government of each of these countries considers this level of fertility too low (UN 2003).

Since 2003 Taiwan's population has been declining, and Taiwan has also had a fertility rate which is below replacement level. The current Taiwan fertility rate is well below dropped to 1.23 children per woman, becoming one of the "ultra-low fertility" countries. When the country has with average below-replacement fertility (less than 2.1 children per woman), and is a serious problem. Pirotto (2016) noted that these problem issues bring a wide range of other problems including: an aging society, a shrinking working population, caring for the elderly, pension costs, and an increasing national debt. Also, other problems such as tension with neighboring countries, domestic political pressure, and a weakening economy etc.

Little research has been done on the low fertility will cause to of the problem of education. Such as enrolments difficulties, reduce classes, add the teacher's surplus, more vacant school premises, and the waste of educational resources etc. It is expected that the competition between schools will become more and more intense in the future. Under the impact of this unfavorable factors, competition between high school and vocational schools will be more stringent. Hence, the school management will be more difficult.

In addition, education can thought as an industry, it serves students for learning and study and is subject to market competition in our society. Keeping the longstanding Competitiveness and obtaining competitive advantages among schools have been known to help sustainable operation efficiency for schools. No doubt, In view of the open market system and its possible diverse impacts on the education market in the future, schools can only achieve sustainable 
operations by enhancing their competitiveness and operational performance. Hence, past studies on efficiency analysis on the education industry were conducted mainly from the perspective of school marketing, with enhancement of organizational efficiency being the main objective. For example, to suggested that the marketing function of schools included the following: providing advice on building a successful educational institution to school teachers and supervisors, enhancing the school's reputation, presenting a national identity, providing information on school selection to parents, recruiting new students, pursuing government funding support, raising funds, etc.(Kotler \& Fox ,1994; Connor ,1999).However, considering that the above mentioned research findings were less objective and that the culture in each school differs, the findings in this area cannot be generalized or applied to all schools.

In recent years, many scholars have employed Data Envelopment Analysis (DEA) to analyze the operational efficiency and examine whether the widespread utilization of assessments can effectively enhance growth efficiency in order to improve operations management. According to the statistics, DEA has been applied empirically to more than one thousand cases in fields as diverse as transportation, educational administration, law, forest management, medicine, banking, military maintenance, and administration. Due to an abundance of prior research, the present study only reviewed relevant Taiwanese literature, which revealed that most studies focused on evaluating the operational performance of universities, high schools, middle schools, vocational schools, and national elementary schools (Wang et. al., 1991; Chen, 1998; Gu, 1999; Liu, 2000; Hwang, 2001; Li, 2009; Hwang, 2012).

Our literature review revealed that the CCR and BCC models were most often used for performance evaluation. In truth, the general DEA model always uses the known data to evaluate the school efficiency. However, this study first uses the estimation results to evaluate the future school efficiency. Accordingly, to study the results of the analysis of the status quo and future differences.

Notably, although, the school efficiency is frequently overlooked or dismissed. Up to this point, however, there were few empirical studies of the low fertility problem, and whether affect education problem. Therefore, further research the low fertility problem whether cause to operating efficiency change of the school, to assist policy makers and education leaders in formulating appropriate policies in the future.

\section{Research Methodology}

The purpose of this research is to analyze under the decreasing rate of school students whether really lead to change the efficiency of school management. The efficiencies of school management are measured by DEA. Furthermore, this study uses TFM to analyze that used to smoothing discrete time series in order to forecast population trends and the efficiency of school.

\section{A. Data Envelopment Analysis (DEA)}

The first DEA model, proposed by Charmes et al. (1978) and known as CCR, assumes the DMUs to be assessed operate within a technology where efficient production is characterized by constant returns to scale (CRS).As above is obtained from the following Equation (1):

$$
\begin{gathered}
\operatorname{Max} h_{k}=\frac{\sum_{r=1}^{s} u_{r} y_{r k}}{\sum_{i=1}^{m} v_{i} x_{i k}} \\
\text { s.t } \frac{\sum_{r=1}^{s} u_{r} y_{r j}}{\sum_{i=1}^{m} v_{i} x_{i j}} \leq 1 \quad, \quad j=1, \ldots, n \\
u_{r}, v_{i} \geq \varepsilon>0, \quad r=1, \ldots \ldots . ., \quad i=1, \ldots \ldots . m
\end{gathered}
$$

where $x_{i j}$ is the amount of the $\mathrm{i}$-th input to DMU j,C is the amount of the $\mathrm{r}$-th output to DMU $\mathrm{j} ;{ }^{u_{r}}, v_{i}$ are called $\mathrm{r}$ virtual multiplier output and i virtual input multiplier; The value of $h_{k}$ obtained is termed the relative efficiency and is 
called the CCR efficiency, the $\varepsilon$ is a non-Archimedean positive element smaller any real number $\left(10^{-6}\right)$,the CCR model is called non-Archimedean small number.

Banker et al. (1984) modified this basic model to permit the assessment of the productive efficiency of DMUs where efficient production is characids by variable returns to scale(VRS). The VRS model, known as BCC, differs from the basic CCR model only in that in includes in the previous formulation the convexity constraint .It follows from what has been the side that the add a limit $\sum_{i=1}^{m} V_{i} X_{i k}=1$, Convert it to the linear programming model.As above is obtained from the following Equation (2):

$$
\begin{gathered}
\operatorname{Min}\left[\theta-\varepsilon\left(e^{t} S^{-}+e^{t} s^{+}\right)\right] \\
\text {s.t }\left\{\begin{array}{l}
\sum_{k=1}^{n} X_{i k} \lambda_{k}+S^{-}=\theta X_{i j} \\
\sum_{k=1}^{n} X_{r k} \lambda_{k}-S^{+}=\theta X_{r k} \\
\sum_{i=1}^{n} \lambda_{i}=1 \\
\lambda_{i} \geq 0, k=1,2, \ldots, n \\
S^{-} \geq 0, S^{+} \geq 0
\end{array} \quad(\mathrm{i}=1, \ldots, \mathrm{I}, \mathrm{r}=1, \ldots, \mathrm{R})\right.
\end{gathered}
$$

In summary, the following equation can be obtained for computing efficiencies:

Technical Efficiency $(\mathrm{TE})=$ Pure Technical Efficiency $(\mathrm{PTE}) \times$ Scale Efficiency $(\mathrm{SE})$

Most scholars generally use Data Envelopment Analysis (DEA) in school efficiency studies. In fact, the Technical Efficiency (TE) results obtained by the traditional DEA model that the relative efficiency value does not denote absolute efficiency. Furthermore, although DEA has some incomparable advantages of parameter estimation methods, it will lead to the deviation of efficiency evaluation in the case of small samples and it ignores the problem of the statistical test.

\section{B. Bootstrap DEA model}

As commented by Hosseinzadeha, Smythb, Valadkhania, and Lea (2016), the main shortcomings of DEA is its deterministic nature. The estimated frontier output (or input) depends on the particular combination of input-output mix and a different observed sample set would lead to a differently estimated frontier. The estimated technical efficiency would thus be different from one sample to another. In order to find a confidence interval covering possible statistical errors, this study consider the sampling distribution of the frontier output (or input). Hence, recent researches have suggested that the Bootstrap DEA is one of the stochastic DEA approaches developed to overcome this shortcoming. We have finally decided to adopt this smooth bootstrapping procedure developed by Simar and Wilson (1998) to obtain statistical inference for DEA estimates of technical efficiency.

The smooth bootstrap DEA algorithm for output oriented technical efficiency can be implemented in the following steps (Zhuo \& Wang, 2011; Chang \& Zhi, 2011):

(1) Use the Decision Making Unit (DMU) efficiency score $\hat{\theta}_{i}$ (i. e., $h_{k}$ in Equation 1), where i $=1,2, \ldots$, n, obtained from the DEA estimation.

(2) Obtain $\hat{\beta}_{i}^{*}$ by repeatedly sampling through $\left(\hat{\theta}_{1}, \hat{\theta}_{2}, \ldots, \hat{\theta}_{n}\right)$.

(3) Use the formula $x_{i}^{*}=\hat{\theta}_{i} x_{i} / \hat{\beta}_{i}^{*}$, to adjust input $\mathrm{x}_{i}$.

(4) Apply the DEA model to the adjusted input and original output to obtain the efficiency score $\hat{\theta}_{i}^{*}$, where $\mathrm{i}=1,2, \ldots$, $\mathrm{N}$.

(5) Repeat steps (1)-(4) B times, and calculate the deviation of efficiency score ( $\hat{\theta}_{i}$ obtain the corrected efficiency $\left.\operatorname{score} \theta_{i}^{\prime}\right)$.

$$
\left\{\begin{array}{c}
\widehat{\widehat{b l a s}_{\iota}}=\frac{1}{B} \sum_{b=1}^{B} \hat{\beta}_{i b}^{*}-\hat{\theta}_{i} \\
\theta_{i}^{\prime}=\hat{\theta}_{i}-\widehat{b \iota a s}_{\iota}
\end{array}\right.
$$

Where $\mathrm{i}=1,2, \ldots, .$. 


\section{Trend Forecasting Model (TFM)}

Trend forecasting model is use to forecast the numbers of school students of high schools can be shown the following Equation (4).

Where

$$
\mathrm{y}_{t}=\alpha+\beta \mathrm{T}+\varepsilon_{t}
$$

$\mathbf{y}_{\boldsymbol{t}}$ : The numbers of school students of high schools in New Taipei City at time $\mathrm{t}$

T: Time trend

$\boldsymbol{\alpha}, \boldsymbol{\beta}$ : Coefficients

$\boldsymbol{\varepsilon}_{\boldsymbol{t}}$ : Disturbance terms, $\varepsilon_{t} \sim$ iid $\mathrm{N}\left(0, \sigma^{2}\right)$

\section{Empirical Results and Analysis}

\section{A. Results of student number trends Analysis for TFM mode}

We utilize our proposed TFM model to study the annual change of student number, from 2011 to 2016 . These data are published by New North City Government.

In this study, we follow the TFM model on the Equation (4) of Section 3. During the 2011 to 2016 period are treated as trial data to conduct the TFM model student of number trends and then forecast student of number trends from 2017 to 2019 of three years. In this process, the original observed data of 2011 to 2016 is used as the test data to evaluate the forecasting power of the proposed model. The detailed forecasting stages are described as follows.

Based on statistical analysis, the empirical results are good fit with R2 $=0.927$ in model. An F-test analysis indicated a significant difference for forecast population trends $(\mathrm{F}=50.423, \mathrm{P}=0.002)$ in Table 1. In this study, forecast population trends model setups can be described as follows (5):

Table 1. TFM model results

\begin{tabular}{lllll}
\hline Variable & Estimated Coefficients & Std. Error & t-statistic & P-value \\
\hline $\mathbf{C}$ & 2033.332 & 2.802404 & 725.567 & $0.000^{* * *}$ \\
\hline Time trends(T) & -0.00159 & $2.24 \times 10^{-5}$ & -7.1 & $0.0021^{* * *}$ \\
\hline $\mathrm{R}^{2}=0.927$ & $\mathrm{~F}=50.423$ & $\mathrm{P}=0.002$ & Adjusted $\mathrm{R}^{2}=0.908$ &
\end{tabular}

Source: This Study

Note: T-value is an indicator of whether the explanatory variable has significant effects on the explained variables; and $* * *, * *$, and $*$ denote significance at the $1 \%, 5 \%$, and $10 \%$ levels, respectively.

$$
\hat{\mathrm{y}}_{t}=2033.33-0.000159 \mathrm{~T}
$$

The next part of the analysis used of forecast population trends model equation (5) to examine the number of school students changes and estimate the number of school students from 2017 to 2019 (Table 2).

Table 2. The number of school students to analysis and estimate

\begin{tabular}{lll}
\hline Year & Number of school students & Reduce rate \\
\hline $\mathbf{2 0 1 1}$ & 136231 & \\
\hline $\mathbf{2 0 1 2}$ & 132204 & 0.030 \\
\hline $\mathbf{2 0 1 3}$ & 130301 & 0.015 \\
\hline $\mathbf{2 0 1 4}$ & 125520 & 0.038 \\
\hline $\mathbf{2 0 1 5}$ & 116039 & 0.082 \\
\hline $\mathbf{2 0 1 6}$ & 106199 & 0.093 \\
\hline $\mathbf{2 0 1 7}$ & 96359.73 (estimate) & 0.102 \\
\hline $\mathbf{2 0 1 8}$ & 86520.46 (estimate) & 0.114 \\
\hline $\mathbf{2 0 1 9}$ & 76681.19 (estimate) & 0.128
\end{tabular}

Source: This Study 


\section{B. Results of Efficiency Analysis for Bootstrap DEA model}

The efficiency analysis of this study mainly comprised three main sections. Section 1 describes the study objects and variable for inputs and outputs in this study. Section 2 presents data description and correlation analysis between inputs and outputs. Finally, Section 3 analyses the efficiency analysis of Bootstrap DEA efficiency model.

\section{Study Objects and Variable for Inputs and Outputs in This Study}

The study objects and variable selection for inputs and outputs in this study are described as follows:

\section{a. Study Objects}

The research subjects of this study consisted primarily of vocational and senior high schools in the Xindian District of New Taipei City. From the Ministry of Education and Board of Education of New Taipei City, this District has nine schools in all. Subjects were divided into two groups, to represent the characteristics of (1) the vocational schools and (2) senior high schools. The names and characteristics of the schools are provided in Table 3.

Table 3. School name and characteristics

\begin{tabular}{cllc}
\hline NO & School name & Category & Group \\
\hline $\mathbf{1}$ & Juang Jing Vocational High School & Vocational High School & 1 \\
\hline $\mathbf{2}$ & $\begin{array}{l}\text { Kai Ming Senior Technical and Commercial Vocational } \\
\text { School }\end{array}$ & Vocational High School & 1 \\
\hline $\mathbf{3}$ & $\begin{array}{l}\text { Nan Chiang Industrial and Commercial Senior High } \\
\text { School }\end{array}$ & Vocational High School & 1 \\
\hline $\mathbf{4}$ & $\begin{array}{l}\text { Neng Ren Home Economic And Commercial Vocational } \\
\text { High School }\end{array}$ & Vocational High School & 1 \\
\hline $\mathbf{5}$ & New Taipei Municipal Hsin Tien Senior High school & Senior High School & 2 \\
\hline $\mathbf{6}$ & New Taipei Municipal An Kang High School & Complete school & 2 \\
\hline $\mathbf{7}$ & Our Lady Of Providence Girls' High School & Senior High School & 2 \\
\hline $\mathbf{8}$ & Chi Jen Senior High School & Senior High School & 2 \\
\hline $\mathbf{9}$ & Kang Hsuan High School & Senior High School & 2 \\
\hline
\end{tabular}

Source: This Study

Note: group 1 indicated the vocational high school group, group 2 indicated senior high school group.

\section{b. Variables Selection}

In this paper, the input-output variables definitions of Xindian public and private vocational schools in Xinbei District, Taiwan are listed in Table 4 and Table 5. The including four input variables: academic department, the number of teachers, adjunct teacher and staff. There are one output variables: number of students. To evaluating operational efficiency for vocational and senior high schools in Xindan area.

Table 4. The five major indicators and definition for schools in Xinbei District

\begin{tabular}{rlcl}
\hline NO & Indicators & Code & Definition \\
\hline $\mathbf{1}$ & academic department & $x_{1}$ & Total academic department of the school \\
\hline $\mathbf{2}$ & number of teachers & $x_{2}$ & The total number of teachers. \\
\hline $\mathbf{3}$ & adjunct instructor & $x_{3}$ & Not a full-time employee of the school. \\
\hline $\mathbf{4}$ & staff & $x_{4}$ & The total number of staffs. \\
\hline $\mathbf{5}$ & number of school students & $y_{1}$ & The number of school students. \\
\hline
\end{tabular}

Source: This Study 
Table 5. The model of input and output definition for schools in Xinbei District

\begin{tabular}{clcl}
\hline NO & Indicators & Code & Definition \\
\hline $\mathbf{1}$ & academic department & $x_{1}$ & Input Indicator \\
\hline $\mathbf{2}$ & number of teachers & $x_{2}$ & Input Indicator \\
\hline $\mathbf{3}$ & adjunct teacher & $x_{3}$ & Input Indicator \\
\hline $\mathbf{4}$ & staff & $x_{4}$ & Input Indicator \\
\hline $\mathbf{5}$ & number of school students & $y_{1}$ & Output Indicator
\end{tabular}

Source: This Study

Prior to the establishment of the empirical model, we list as many preliminary assessment factors as possible for the input and output units. Any variable that may affect the DMU performance dimension is included for investigation so that the pre-setting of output function type was required. Pearson's correlation analysis is then used for preliminary analysis of the level of correlation between the inputs and outputs (Table 6).

Table 6. Correlation test and analysis

\begin{tabular}{cccccc}
\hline & $x_{1}$ & $x_{2}$ & $x_{3}$ & $x_{4}$ & $y_{1}$ \\
\hline$x_{1}$ & 1 & 0.558 & $0.681^{*}$ & 0.344 & $0.714^{*}$ \\
\hline$x_{2}$ & & 1 & 0.237 & $0.770^{*}$ & 0.637 \\
\hline$x_{3}$ & & & 1 & 0.197 & $0.722^{*}$ \\
\hline$x_{4}$ & & & & 1 & $0.718^{*}$ \\
\hline$y_{1}$ & & & & & 1 \\
\hline
\end{tabular}

Source: This Study.

Note: $* * *, * *$, and $*$ denote significance at the $1 \%, 5 \%$, and $10 \%$ levels, respectively.

The result should be consistent with the results of the variable analysis showing positive correlation and the defined concepts of the DEA input and output variables. Table 7 shows the results of the analysis of sample statistical data of the confirmed input and output items. The finalized input and output units are selected in accordance with the objective of this study, as explained below.

Table 7. Analysis of sample statistical data

\begin{tabular}{|c|c|c|c|c|c|}
\hline & $x_{1}$ & $x_{2}$ & $x_{3}$ & $x_{4}$ & $y_{1}$ \\
\hline Max & 5 & 190 & 165 & 94 & 4899 \\
\hline Min & 1 & 36 & 0 & 7 & 597 \\
\hline Average & 2.33 & 105.33 & 46.73 & 24.69 & 2037.58 \\
\hline SD & 1.261 & 37.368 & 41.508 & 19.017 & 1368.977 \\
\hline
\end{tabular}

Source: This Study

\section{Efficiency Analysis}

Regarding efficiency analysis of this study mainly comprised two main sections. Section 1 to efficiency analysis of the school with current state and Section 2 indicates efficiency analysis of the school with the future tendency.

\section{a. Efficiency analysis of the school with current state (2011-2016)}

The results that the nine schools were divided into two groups to represent of (1) the vocational schools in table 8 and (2) senior high schools in Table 9.

We utilize our proposed TFM model to study the annual change of student's population, from 2011 to 2016 . Table 2 indicates that the number of students is indeed reduced year by year in New Taipei City, but the number of decline is 
not great. Therefore, the Bootstrap DEA model is used to conduct the efficiency analysis, followed by estimations and analyses of efficiency values.

Fix on Bootstrap DEA method as we describe in equation (2) of Section 3, we obtain Bootstrap DEA efficiency scores of vocational schools (Group 1) and senior high schools(Group 2 ). Table 8 and Table 9 shows that Group 1 performed better than Group 2 under this analytical model, indicating that the efficiencies of vocational schools were generally better than those of senior high schools; indeed, vocational high schools teach which aims to ensure that students leave not only with the basics they need to earn a high school diploma in the state, but also an industry certification and were therefore able to attract more students, thereby significantly improving their operations. For example, in Group 1, Juangjing vocational high school achieved an average efficiency value of 1 in three of the five years, while the efficiency values of schools in Group 1 more than Group 2 were generally high. The above results show the efficiency value of 1 that in terms of resource allocation, management decisions, and output scale, these schools need not make any improvements or adjustments provided no environmental factors are considered.

In fact, the number of students is reduced have to influences the operational efficiency for vocational and senior high schools. One of the main reasons that the low fertility problem in Taiwan, the number of students (output variable) decreased and overestimate the teacher, adjunct instructor, and staff etc., class size decreases and leads to too many teachers as input in each class. Therefore, resource misallocation in teachers and students and the cost per teacher over counts and hence reduce the school's operational efficiency.

Table 8. Efficiency analysis of the vocational schools with the current state (2011-2016)

\begin{tabular}{|c|c|c|c|c|}
\hline DMU & TE & PTE & SE & TE change \\
\hline Kai Ming 2012 & 1.000 & 1.000 & 1.000 & $* * *$ \\
\hline Kai Ming 2013 & 0.984 & 1.000 & 0.984 & $-2 \%$ \\
\hline Kai Ming 2014 & 0.797 & 0.887 & 0.900 & $-23 \%$ \\
\hline Kai Ming 2015 & 0.670 & 0.752 & 0.892 & $-19 \%$ \\
\hline Kai Ming 2016 & 0.604 & 0.811 & 0.744 & $-11 \%$ \\
\hline Average & \multicolumn{2}{|c|}{0.811} & & \\
\hline Nan Chiang 2012 & 0.732 & 0.892 & 0.820 & $* * *$ \\
\hline Nan Chiang 2013 & 0.732 & 0.891 & 0.821 & $0 \%$ \\
\hline Nan Chiang 2014 & 0.753 & 0.857 & 0.878 & $3 \%$ \\
\hline Nan Chiang 2015 & 0.760 & 0.879 & 0.865 & $1 \%$ \\
\hline Nan Chiang 2016 & 0.775 & 0.847 & 0.915 & $2 \%$ \\
\hline Average & \multicolumn{2}{|c|}{0.751} & & \\
\hline Neng Ren 2012 & 0.852 & 0.889 & 0.959 & $* * *$ \\
\hline Neng Ren 2013 & 0.910 & 0.987 & 0.922 & $6 \%$ \\
\hline Neng Ren 2014 & 0.878 & 0.965 & 0.910 & $-4 \%$ \\
\hline Neng Ren 2015 & 0.817 & 0.841 & 0.971 & $-7 \%$ \\
\hline Neng Ren 2016 & 0.909 & 0.910 & 0.999 & $10 \%$ \\
\hline Average & \multicolumn{2}{|c|}{0.873} & & \\
\hline Juang Jing 2012 & 1.000 & 1.000 & 1.000 & $* * *$ \\
\hline Juang Jing 2013 & 0.933 & 0.940 & 0.992 & $-7 \%$ \\
\hline Juang Jing 2014 & 0.913 & 0.924 & 0.988 & $-2 \%$ \\
\hline Juang Jing 2015 & 1.000 & 1.000 & 1.000 & $9 \%$ \\
\hline Juang Jing 2016 & 1.000 & 1.000 & 1.000 & $0 \%$ \\
\hline Average & & & & \\
\hline Total Average & & & & \\
\hline
\end{tabular}

Source: This Study 
Table 9. Efficiency analysis of the senior high schools with the current state (2011-2016)

\begin{tabular}{|c|c|c|c|c|}
\hline DMU & TE & PTE & SE & TE change \\
\hline An Kang 2012 & 0.393 & 0.566 & 0.694 & $* * *$ \\
\hline An Kang 2013 & 0.363 & 0.471 & 0.770 & $-8.26 \%$ \\
\hline An Kang 2014 & 0.543 & 0.655 & 0.830 & $33.15 \%$ \\
\hline An Kang 2015 & 0.528 & 0.884 & 0.598 & $-2.84 \%$ \\
\hline An Kang 2016 & 0.563 & 1.000 & 0.563 & $6.22 \%$ \\
\hline Average & \multicolumn{2}{|c|}{0.478} & & \\
\hline Providence 2012 & 0.678 & 1.000 & 0.678 & $* * *$ \\
\hline Providence 2013 & 0.738 & 1.000 & 0.738 & $8.13 \%$ \\
\hline Providence 2014 & 0.715 & 1.000 & 0.715 & $-3.22 \%$ \\
\hline Providence 2015 & 0.739 & 1.000 & 0.739 & $3.25 \%$ \\
\hline Providence 2016 & 0.778 & 1.000 & 0.778 & $5.01 \%$ \\
\hline Average & \multicolumn{2}{|c|}{0.723} & & \\
\hline Chi Jen 2012 & 1.000 & 1.000 & 1.000 & $* * *$ \\
\hline Chi Jen 2013 & 0.866 & 1.000 & 0.866 & $-15.47 \%$ \\
\hline Chi Jen 2014 & 0.620 & 1.000 & 0.620 & $-39.68 \%$ \\
\hline Chi Jen 2015 & 0.604 & 1.000 & 0.604 & $-2.65 \%$ \\
\hline Chi Jen 2016 & 0.661 & 1.000 & 0.661 & $8.62 \%$ \\
\hline Average & \multicolumn{2}{|c|}{0.751} & & \\
\hline Kang Hsuan 2012 & 0.443 & 1.000 & 0.443 & $* * *$ \\
\hline Kang Hsuan 2013 & 0.909 & 1.000 & 0.909 & $51.27 \%$ \\
\hline Kang Hsuan 2014 & 1.000 & 1.000 & 1.000 & $9.10 \%$ \\
\hline Kang Hsuan 2015 & 0.952 & 1.000 & 0.952 & $-5.04 \%$ \\
\hline Kang Hsuan 2016 & 1.000 & 1.000 & 1.000 & $4.80 \%$ \\
\hline Average & & & & \\
\hline Hsin Tien 2012 & 0.763 & 0.863 & 0.884 & $* * *$ \\
\hline Hsin Tien 2013 & 0.767 & 0.867 & 0.885 & $0.52 \%$ \\
\hline Hsin Tien 2014 & 0.734 & 0.840 & 0.874 & $-4.50 \%$ \\
\hline Hsin Tien 2015 & 0.719 & 0.832 & 0.865 & $-2.09 \%$ \\
\hline Hsin Tien 2016 & 0.720 & 0.832 & 0.865 & $0.14 \%$ \\
\hline Average & & & & \\
\hline Total Average & & & & \\
\hline
\end{tabular}

Source: This Study

\section{b. Efficiency Analysis of the School with the Future Tendency (2017-2019).}

The results that the nine schools were divided into two groups to represent of (1) the vocational schools in table 10 and (2) senior high schools in Table 11.

We utilize our proposed TFM model results to estimate of the student population, from 2017 to 2019. Table 2 indicates that the number of students is indeed reduced year by year in New Taipei City. Moreover, the number of student's declines is severe. Therefore, this paper attempts to use the Bootstrap DEA model to conduct the future efficiency analysis, followed by estimations and analyses of efficiency values with the future tendency.

The Table 10 and Table 11 show that the TE of the schools in the next three years will be the highest decrease in 2016 to 2017 , and each school overall TE will decrease by about $10 \%$. In fact, the decreasing rate of school students' problem to have a significant impact on the operational efficiency for vocational and senior high schools. The low fertility problem brings about the number of students (output variable) decreased and causing the schools total 
efficiency to fall below 1. Furthermore, overestimate the teacher, adjunct instructor, and staff etc., class size decreases and leads to too many teachers as (input variable). Finally, resource misallocation in teachers and students and the cost per teacher over counts and hence reduce the school's operational efficiency.

Theoretically, the subdivision of total efficiency under the DEA model reveals that the source of inefficiency is the lack of pure technical efficiency or scale efficiency, while total efficiency (representing the total efficiency of individual DMUs) is the product of pure technical efficiency and scale efficiency. The Table 10 shows that the pure technical efficiency and scale efficiency have a significant impact on the operational efficiency for vocational school. In contrast, The Table 11 shows that the scale efficiency has a significant impact on the operational efficiency for senior high schools. The decreasing rate of school students' problem points out that this problem real to have a significant impact on the operational efficiency and due to most the school's inefficiency main has suffered by scale efficiently. It implies that the larger the school, the economics of scale can be accomplished when outputs expand (such as the number of students (output variable)) and then cause school's operational efficiency. In contrast, the low fertility problem brings about the number of students (output variable) decreased may directly affect school of scale efficiency and causing the schools total efficiency to fall below 1 .

On the other hand, the schools know that the low fertility problem factors caused school of scale efficiency decreased. Thus, these schools need to make any improvements or adjustments in terms of resource allocation, management decisions, and output scale. Finally, the schools lessen the impact by the low fertility problem brings about the number of students (output variable) decreased and the schools TE to fall below

\section{Longitudinal model: comparison by type of school}

From the results, the schools know that the low fertility problem factors caused school of total efficiency to fall below 1. It can be said that on average, the vocational schools perform better than senior high schools. In this study, we consider whether the public or private school has different operational efficiency by the low fertility problem. Our empirical results depict that operational efficiency of public school is better than that of private school. The public school accessory equipment comes from the budget of the central government, but the private school accessory equipment of budget comes from oneself school. When the low fertility problem has begun to make some impact, this school would make any improvements or adjustments in terms of resource allocation, management decisions, and output scale.

Table 10. Efficiency analysis of the vocational schools with the future tendency (2017-2019)

\begin{tabular}{|c|c|c|c|c|c|c|c|}
\hline DMU & TE & & PTE & & SE & TE change & Note \\
\hline Kai Ming 2017 & 0.542 & & 0.770 & & 0.705 & $-11.44 \%$ & estimate \\
\hline Kai Ming 2018 & 0.535 & & 0.765 & & 0.700 & $-1.31 \%$ & estimate \\
\hline Kai Ming 2019 & 0.526 & & 0.759 & & 0.694 & $-1.71 \%$ & estimate \\
\hline Average & & 0.534 & & 0.765 & & & \\
\hline Nan Chiang 2017 & 0.696 & & 0.791 & & 0.880 & $-11.35 \%$ & estimate \\
\hline Nan Chiang 2018 & 0.687 & & 0.785 & & 0.875 & $-1.31 \%$ & estimate \\
\hline Nan Chiang 2019 & 0.676 & & 0.777 & & 0.870 & $-1.63 \%$ & estimate \\
\hline Average & & 0.686 & & 0.784 & & & \\
\hline Neng Ren 2017 & 0.817 & & 0.838 & & 0.974 & $-11.26 \%$ & estimate \\
\hline Neng Ren 2018 & 0.806 & & 0.830 & & 0.970 & $-1.36 \%$ & estimate \\
\hline Neng Ren 2019 & 0.793 & & 0.821 & & 0.966 & $-1.64 \%$ & estimate \\
\hline Average & & 0.805 & & 0.830 & & & \\
\hline Juang Jing 2017 & 0.898 & & 0.917 & & 0.979 & $-11.36 \%$ & estimate \\
\hline Juang Jing 2018 & 0.886 & & 0.908 & & 0.976 & $-1.35 \%$ & estimate \\
\hline Juang Jing 2019 & 0.872 & & 0.896 & & 0.973 & $-1.61 \%$ & estimate \\
\hline Average & & 0.885 & & 0.907 & & & \\
\hline Total Average & & 0.728 & & & & & \\
\hline
\end{tabular}

Source: This Study 
Table 11. Efficiency analysis of the senior high schools with the future tendency (2017-2019)

\begin{tabular}{|c|c|c|c|c|c|c|c|c|}
\hline DMU & TE & & PTE & & SE & & TE change & Note \\
\hline An Kang 2017 & 0.505 & & 0.807 & & 0.626 & & $-11.49 \%$ & estimate \\
\hline An Kang 2018 & 0.498 & & 0.784 & & 0.636 & & $-1.41 \%$ & estimate \\
\hline An Kang 2019 & 0.491 & & 0.757 & & 0.648 & & $-1.43 \%$ & estimate \\
\hline Average & & 0.498 & & 0.783 & & 0.637 & & \\
\hline Providence 2017 & 0.699 & & 1 & & 0.699 & & $-11.30 \%$ & estimate \\
\hline Providence 2018 & 0.689 & & 1 & & 0.689 & & $-1.45 \%$ & estimate \\
\hline Providence 2019 & 0.679 & & 1 & & 0.679 & & $-1.47 \%$ & estimate \\
\hline Average & & 0.689 & & 1.000 & & 0.689 & & \\
\hline Chi Jen 2017 & 0.594 & & 1 & & 0.594 & & $-11.28 \%$ & estimate \\
\hline Chi Jen 2018 & 0.586 & & 1 & & 0.586 & & $-1.37 \%$ & estimate \\
\hline Chi Jen 2019 & 0.577 & & 1 & & 0.577 & & $-1.56 \%$ & estimate \\
\hline Average & & 0.586 & & 1.000 & & 0.586 & & \\
\hline Kang Hsuan 2017 & 0.898 & & 1 & & 0.898 & & $-11.36 \%$ & estimate \\
\hline Kang Hsuan 2018 & 0.886 & & 1 & & 0.886 & & $-1.35 \%$ & estimate \\
\hline Kang Hsuan 2019 & 0.872 & & 1 & & 0.872 & & $-1.61 \%$ & estimate \\
\hline Average & & 0.885 & & 1.000 & & 0.885 & & \\
\hline Hsin Tien 2017 & 0.647 & & 0.773 & & 0.837 & & $-11.28 \%$ & estimate \\
\hline Hsin Tien 2018 & 0.638 & & 0.766 & & 0.833 & & $-1.41 \%$ & estimate \\
\hline Hsin Tien 2019 & 0.628 & & 0.758 & & 0.829 & & $-1.59 \%$ & estimate \\
\hline Average & & 0.638 & & 0.766 & & 0.833 & & \\
\hline
\end{tabular}

Source: This Study

On the other hand, the above results show that when government's free tuition policy (which forms part of the 12-year Compulsory Education Policy) executed after years 2007, it has helped to improve the operational efficiency of school resources, in particular, vocational schools. Thus, vocational schools had access to more resources (government grants), and therefore, the vocational schools perform better than senior high schools.

\section{Concluding Remarks}

In this study, we firstly apply TFM model to modeling by 2011 to 2016 data and then establishing forecast model to forecast population trends from 2017 to 2019 and then justify apply Bootstrap data envelopment analysis (DEA) model to analyze the relative efficiencies of schools and under the decreasing rate of school students whether really lead to change the efficiency of school management.

We utilize our proposed TFM model to study the annual change of student's population, from 2011 to 2016 . The results show that the number of students is indeed reduced year by year in New Taipei City, but the number of declines is not great, from 2011 to 2016. Conversely, the number of student's declines has been great, from 2016 to 2017 .

The results show that Group 1 performed better than Group 2 under this analytical model, indicating that the efficiencies of vocational schools were generally better than those of senior high schools, from 2011 to 2016. In fact, he vocational high schools teach which aims to ensure that students leave not only with the basics they need to earn a high school diploma in the state, but also an industry certification and were therefore able to attract more students, thereby significantly improving their operations. For example, in Group 1, Juangjing vocational high school achieved an average efficiency value of 1 in three of the five years, while the efficiency values of schools in Group 1 more than Group 2 were generally high. The above results show the efficiency value of 1 that in terms of resource allocation, management decisions, and output scale, these schools need not make any improvements or adjustments provided no environmental factors are considered.

The research indicated that the TE of the schools in the next three years will be the highest decrease in 2016 to 2017, and each school overall TE will decrease by about $10 \%$. In fact, the decreasing rate of school students' problem to have 
a significant impact on the operational efficiency for vocational and senior high schools. The low fertility problem brings about the number of students (output variable) to decrease and cause the schools total efficiency to fall below 1 . Furthermore, overestimate the teacher, adjunct instructor, and staff etc., class size decreases and leads to too many teachers as (input variable).Finally, resource misallocation in teachers and students and the cost per teacher over counts and hence reduce the school's operational efficiency.

From the results, it can be said that on average, the vocational schools perform better than senior high schools. Our empirical results depict that operational efficiency of public school is better than that of private school. The public school accessory equipment comes from the budget of the central government, but the private school accessory equipment of budget comes from oneself school. When the low fertility problem has begun to make some impact, this schools would make any improvements or adjustments in terms of resource allocation, management decisions, and output scale. On the other hand, the above results show that when government's free tuition policy (which forms part of the 12-year Compulsory Education Policy) executed after years 2007, it has helped to improve the operational efficiency of school resources, in particular, vocational schools. Thus, vocational schools had access to more resources (government grants), and therefore, the vocational schools perform better than senior high schools.

As mentioned above, the low fertility problem factors caused school of total efficiency to fall below 1. In addition, the government also proposes to raise the fertility policy, for example, the government subsidies schools of tuition. It implies that the larger the school, the economics of scale can be accomplished when outputs expand (such as the numbers of students (output variable)) and then cause school's operational efficiency. In contrast, the low fertility problem brings about the numbers of decreased students (output variable) may directly affect school of scale efficiency and causing the schools total efficiency to fall below Thus, this confirmed the school needed for innovation, operations management, and be able to ahead of our competitors.

Lastly, the conclusions and recommendations presented here are based on the models constructed, sample data collected, and research methodologies employed for this study. Hence, it is necessary to take into consideration the current situation and changes in the environment that are impacting the public and private high schools and vocational schools in the Taiwan District, so any application of our findings can be further tailored to yield more accurate conclusions.

\section{References}

Banker, R.D. (1984). Estimating most productive scale size using data envelopment analysis. European Journal of Operational Research, 17, 35-44. https://doi.org/10.1016/0377-2217(84)90006-7

Basten, S., \& Sobotka, T. (2013). Future fertility in low fertility countries (No. 5/2013). Vienna Institute of Demography Working Papers.

Brown, R.G., \& Meyer, R.F. (1961). The fundamental theorem of exponential smoothing. Operations Research, 9(5), 673-685. https://doi.org/10.1287/opre.9.5.673

Chang, Q.T., \& Zhi, P. W. (2011). Analysis of regional differences and causes of technical efficiency-based on three-stage DEA and bootstrap methods. Res Dev Manage, 6, 91-99.

Charnes, A., Cooper, W.W., \& Rhodes, E.L. (1978). Measuring the efficiency of decision making units. European Journal of Operational Research, 2, 429-444. https://doi.org/10.1016/0377-2217(78)90138-8

Chen, R.F. (1998). Evaluation of Educational Quality in Universities and Colleges in Taiwan Using Data Envelopment Analysis. Academic Journal of Kaohsiung Institute of Science and Technology, 28, 227-238.

Connor, M. (1999). Making the right choice: how students choose universities and colleges, report by The Institute for Employment Studies to CVCP, HEFCE and UCAS, Institute for Employment Studies, Brighton, 1-75.

Cutler, D. M., Poterba, J. M., Sheiner, L. M., Summers, L. H., \& Akerlof, G. A. (1990). An aging society: opportunity or challenge? Brookings papers on economic activity, 1, 66-73. https://doi.org/10.2307/2534525

Faruqee, H., \& Mühleisen, M. (2002). Population aging in Japan: demographic shock and fiscal sustainability. Japan and the world economy, 15(2), 185-210. https://doi.org/10.1016/S0922-1425(02)00017-8

Gu, Z. Y. (1999). A study on the Productivity Assessment and Integration Model of Resource Allocation in Higher Education Units. Journal of Management and Systems, 6(3), 347-364.

Hosseinzadeha, A., Smythb, R., Valadkhania, A., \& Lea, V. (2016, September). Analyzing the efficiency performance of major Australian mining companies using bootstrap data envelopment analysis. Economic Modelling, 57, 26-35. https://doi.org/10.1016/j.econmod.2016.04.008 
Hwang, J. X. (2001). Evaluating the Efficiencies of National High Schools in Taiwan: Application of Data Envelopment Analysis (MA Thesis - unpublished). Chiayi City: National Chung Cheng University.

Hwang, Y. X. (2012). Comparative Analysis of the Operational Performance of Public and Private High Schools, Middle Schools, and Vocational Schools with Schools in the Sindian District of New Taipei City as Examples (MA Thesis - unpublished), Taichung: Asia University.

Kotler, P., \& Fox, K. F. A. (1995). Strategic marketing for educational institutes (2nd ed.). Englewood Cliffs, NJ: Prentice Hall.

Li, C. Y. (2009). Assessment of the Operational Efficiency of Vocational High Schools: Data Envelopment Analysis. Xiong Gong Academic Journal.

Lindh, T., \& Malmberg, Bo. (1999). Age structure effects and growth in the OECD, 1950-1990. Journal of Population Economics, 12(3), 431-449. https://doi.org/10.1007/s001480050107

Liu, M. C. (2000). A Study on the Assessment of the Management Efficiencies of Education at Vocational High Schools in Taiwan: Applied Analysis of the DEA Model (MA Thesis - unpublished). Nantou County: National Chi Nan University.

MacKellar, L., \& Ermolieva, T. (2004). Economic Impacts of Population Aging in Japan. Edward Elgar Publishing.

Mcdonald, P. (2005, May). Low fertility in Singapore: causes, consequences and policies. In forum on population and development in East Asia, Beijing, pp. 16-17.

Montgomery, D. C., Johnson, L. A., \& Gardiner, J. S. (1990). Forecasting and time series analysis. McGraw-Hill Companies.

Pirotto, C. J. (2016). Japan's population crisis: Determining the effectiveness of Japanese population policy. Doctoral dissertation, San Diego State University.

United Nations. (2003). World Population Policies. New York: United Nations, Department of Economic and Social Affairs.

Wang, G. M., \& Gu, Z. Y. (1991). A Study on the Application of DEA in Educational Assessment. Modern Education, 6(1), 118-127.

Zhuo, L., \& Wang, B. Y. (2011). Study on convergence of the measurement and randomness of coal efficiency based on DEA, Bus Res., 3, 146-151. 